\title{
A Rapid Mercury Droplet Electrode Polarography Method for Determination of Blood Lead Level in Lead Poisoned People
}

\author{
Authors \\ Golriz Hosseini ${ }^{1}$, Jalal Hanaie ${ }^{1}$, Ali Ostadi², Javad Valipor ${ }^{3}$, Aliasghar Hamidi ${ }^{1,4}$, Saeed Ghanbarzadeh ${ }^{5}$
}

Affiliations

1 Department of Medicinal Chemistry, Faculty of Pharmacy, Tabriz University of Medical Sciences, Tabriz, Iran

2 Sian Hospital, Department of Internal Medicine, Faculty of Medicine, Tabriz University of Medical Sciences, Tabriz, Iran

3 Department of Analytical Chemistry, Faculty of Chemistry, Tabriz University, Tabriz, Iran

4 Food and Drug Safety Research Center, Tabriz University of Medical Sciences, Tabriz, Iran

5 Department of Pharmaceutics, Faculty of Pharmacy, Zanjan University of Medical Sciences, Zanjan, Iran

Key words chemistry, diagnostics, drug dependence, drugs of abuse, toxicology

received $\quad 06.05 .2020$

accepted $\quad 05.10 .2020$

published online 12.11 .2020

Bibliography

Drug Res 2021; 71: 193-198

DOI 10.1055/a-1293-6924

ISSN 2194-9379

(C) 2020. Thieme. All rights reserved.

Georg Thieme Verlag KG, Rüdigerstraße 14,

70469 Stuttgart, Germany

\section{Correspondence}

Aliasghar Hamidi

Department of Medicinal Chemistry, Faculty of Pharmacy

Tabriz University of Medical Sciences

Golgasht Street

5166/15731 Tabriz

Iran

Tel.: 00984133359552

ali.asgh.hamidi@gmail.com
Saeed Ghanbarzadeh

Gavazang St, Faculty of Pharmacy, Zanjan University of Medical Sciences

45139-56184 Zanjan

Iran

P.O.Box 45195-1338

Tel.: 00982433456743

s_ghanbarzadeh@yahoo.com

\section{ABSTRACT}

Background Lead is a hazardous heavy metal, which causes many problems in the human body. Unfortunately, recent reports showed that smugglers and opium sellers add lead to drugs during the production procedure in order to increase its weight and cost.

Purpose The aim of this study was development of a rapid and accurate method for measurement of blood lead levels (BLL) in the oral and inhaled opiate abuser people.

Methods BLL in samples obtained from the oral and inhaled opium addicted patients referring to Sina Hospital in Tabriz, Iran, during 2017 was compared with healthy control group $(\mathrm{N}=15)$. The wet digestion method was used to prepare whole blood and Mercury Droplet Electrode Polarography (MDEP) method was utilized for measurement of the lead content of digested samples.

Results Results showed that there were significant differences between the BLL of samples obtained from oral $(17.12 \pm 74.61 \mu \mathrm{g} / \mathrm{dL}, \mathrm{p}<0.0003)$ and inhaled $(19.33 \pm 2.257 \mu \mathrm{g} /$ $\mathrm{dL}, \mathrm{p}<0.0001)$ opium addicted groups in comparison with healthy control group $(4.669 \pm 0.3367 \mu \mathrm{g} / \mathrm{dL})$.

Conclusion Based on the results of this study it was observed that BLL in opium addicted people needs to be measured as soon as possible. Furthermore, screening of blood lead concentrations in opium-addicted people with a rapid and accurate MDEP method is very necessary and important.

\section{Introduction}

Lead poisoning is a medical complication, which caused by enhanced levels of lead in the blood. Chronic exposure to the different sources via oral, inhalation, or dermal contact be able to cause toxicity in body system, such as the neurological (including headache, irritability, lethargy, convulsions, muscle weakness, ataxia, tremors and paralysis) haematological (anaemia), gastrointestinal, cardiovascular and renal systems. On the other hand acute expo- 
sures may also cause gastrointestinal disturbances (anorexia, nausea, vomiting, abdominal pain), hepatic and renal damage, hypertension and neurological effects (malaise, drowsiness, encephalopathy, attention problems), which may lead to convulsions and death [1-6]. Many outcomes of lead toxicity are related to its interactions with important components like calcium, enzymes and other proteins [7]. It was reported that up to $99 \%$ of the lead in the blood binds to the red blood cells, and only $1 \%$ is existent in the serum through the diffusion of tissue availability. Approximately $35-40 \%$ of inhaled lead is absorbed in the lungs, and about $60 \%$ come into the bloodstream. Lead is removed by the kidneys, gastrointestinal tract, sweat, and skin or is accumulated in the nails and hair [8]. Lead is a component of different equipment such as home appliances, cosmetics, toys, and colors. Lead can enter into the body from different routes, particularly gastrointestinal and respiratory systems $[9,10]$. Job-related contact is a common cause of lead poisoning that may happens in industrial processes such as melting of lead and its burning, leaded gasoline, pottery, painting, lead containing pipes, battery recycling, pigments, printing centers, and etc. In addition to routine sources of lead exposure, evidence of lead poisoning has been reported among opium consumers, especially in some part of Asia such as Iran and Afghanistan, and some researches have analytically confirmed the presence of lead in opium [1, 2]. Thus, it may cause more dangerous lead poising and healthy problems in people with this type of opium addict [11]. Furthermore, in people with opium addict, the amount of lead taken is higher than the other ways of exposure to lead, as lead in opium addicts is directly taken by inhalation or oral usage. Therefore, lead poisoning is an important concern and it is necessary to determine the level of lead in blood serum to be prevented and cured as early as possible [8]. Although a number of other human tissues and fluids, such as hair, teeth, bone and urine, also reflect lead exposure, the concentration of lead in whole blood has gained wide acceptance as the most useful tool for screening and diagnostic testing $[1,2]$. There are several studies of lead toxicity which use a number of methods to evaluate and determine lead levels in blood serum such as voltammetry, Atomic absorption spectrometry (AAS), flame atomic absorption spectrometry (FAAS), graphite furnace atomic absorption spectrometry (GFAAS), anodic stripping voltammetry (ASV), inductively coupled plasma mass spectrometry (ICP-MS) [12-15]. The polarography is a kind of voltammetry method, which is a rapid, relative simplicity of equipment, cheap and good detection limit (2-3 Ug/dl), for blood lead measurement [16-18]. Specifically if the anodic stripping voltammetry (ASV) combined with the differential pulse polarography (DPP), the detection limit will be 100 times decreased compared with the ordinary polarography [19]. To our knowledge, the polarography has not been used to determine BLL in people with opium addiction. Since the level of lead in blood serum in these people is significantly higher than the low limit of detection it appears that determination of BLL will be accurate enough by using the polarography $[16,20]$. Therefore, the aim of this study was to determine BLL in people with opium addict using the polarography method, which is a rapid, sensitive, and cheaper method compared to other methods.

\section{Materials and Methods}

\section{Apparatus}

BLL measurement was carried out by differential pulse anodic stripping voltammetry (DPASV), combination of ASV and DPP methods, using a 797 VA-trace analyzer, (Metrohm, Herisau, Switzerland). A Voltametric cell containing a hanging drop mercury electrode (HDME) as a working electrode, an $\mathrm{Ag} / \mathrm{AgCl}$ (3M KCl, saturated $\mathrm{AgCl})$ as a reference electrode, and a Pt wire as an auxiliary electrode were used to measure the level of lead in blood serum. A 744 $\mathrm{pH}$ meter (Metrohm), equipped with a combined $\mathrm{Ag} / \mathrm{AgCl}$ glass electrode was used for $\mathrm{pH}$ measurement. Solutions were deoxygenized with high-purity nitrogen for 5 min prior to each experiment, which were performed under a nitrogen flow. All glassware and storage bottles were soaked in $6 \% \mathrm{HNO}_{3}$ overnight and thoroughly washed with deionized water before use.

\section{Reagents and solutions}

The suprapure nitric acid, nitric acid, acetic acid, percholoric acid, hydrocholoric acid, sodium hydroxide, oxalic acid, pure lead of 1000 ppm, mercury and potassium chloride were purchased from Merck Chemical Company (pro- analysis grade) (Darmstadt, Germany). All chemicals and reagents were analytical grade and used without further purification. All experiments were carried out at room temperature. We also used repeated dilutions with deionized double distilled water to prepare low concentration solutions.

\section{Blood serum samples preparation}

$10 \mathrm{~mL}$ of blood sample was taken for the subjects. $2 \mathrm{~mL}$ of the sample together with $2 \mathrm{~mL}$ of suprapure concentrated nitric acid were transferred into a cleaned test tube, and then $2 \mathrm{~mL}$ of $\mathrm{HClO}_{4}$ was added. The resulting solution was heated to nearly boiling point and the appearance of yellow color. Then $2 \mathrm{~mL}$ of nitric acid was added to the solution and heated upto a boiling point for ten minutes, and then on the residual ash, $2 \mathrm{~mL}$ of HCL was added and evaporated until nearly dryness. The acidity of the solution was neutralized with $2 \mathrm{M} \mathrm{NaOH}(\mathrm{pH}=4.6)$. The final sample $(2 \mathrm{~mL})$ was transferred into a $10 \mathrm{~mL}$ volumetric flask and diluted with $8 \mathrm{~mL}$ deionized double distilled water. To protect of the lead, $5 \mathrm{ml}$ of sodium oxalate $(1 \mathrm{mM})$ buffer was added to the final sample (totally $15 \mathrm{~mL}$ ) which was ready for injection into the voltammetry cell [21].

\section{Polargraphic measurements}

In order to determine the amount of lead, $200 \mu \mathrm{L}$ of the final sample were diluted with $10 \mathrm{~mL}$ of distilled water and $1 \mathrm{~mL}$ of acetate buffer ( $1 \mathrm{mM}, \mathrm{pH}=4.6$ ) was added to the voltammetry cell, and then the sample was deoxygenated for $180 \mathrm{~s}$ with nitrogen (99.999\% V/V). The lead measurement was performed using Polargraphy method described elsewhere [22, 23]. Briefly, a fresh mercury drop was ejected from the working electrode, and then the stirrer was started for $30 \mathrm{~s}$ at $-600 \mathrm{mV}$ vs $\mathrm{Ag} / \mathrm{AgCl}$, followed by a reduction of lead in the solution. The potential was swept from $-660 \mathrm{mV}$ to $-200 \mathrm{mV}$ with a sweep rate of $4 \mathrm{mVs}^{-1}$. The technical characteristics of polarography method are shown in $>$ Table 1. As long as the voltage reached to $-420 \mathrm{mV}$, lead was detached from the HMDE (stripping). Then a peak current with the amplitude corresponding to lead concentration was observed in this voltagram. 
- Table 1 Technical characteristics of polarography method

\begin{tabular}{|l|l|}
\hline Working electrode & HMDE \\
\hline stirrer speed & $2000 \mathrm{rpm}$ \\
\hline mode & ASV \\
\hline purge time & $180 \mathrm{~s}$ \\
\hline deposition potential & $-660 \mathrm{mV}$ \\
\hline deposition time & $60 \mathrm{~s}$ \\
\hline equilibration time & $10 \mathrm{~s}$ \\
\hline start potential & $-660 \mathrm{mV}$ \\
\hline end potential & $-200 \mathrm{mV}$ \\
\hline sweep rate & $4 \mathrm{mV} / \mathrm{s}$ \\
\hline peak potential $(\mathrm{Pb})$ & $-420 \mathrm{mV}$ \\
\hline
\end{tabular}

- Table 2 Descriptive statistics (mean \pm SD) of subjects' characteristics in oral, inhale, and control groups.

\begin{tabular}{|l|l|l|l|}
\hline Characteristics & Oral $(\mathbf{n = 1 5})$ & Inhale $(\mathbf{n}=\mathbf{1 5})$ & Control $(\mathbf{n}=\mathbf{1 5})$ \\
\hline Age (year) & $42 \pm 11$ & $39 \pm 15$ & $41 \pm 12$ \\
\hline $\begin{array}{l}\text { Gender }(\%) \text { male/ } \\
\text { female) }\end{array}$ & $86 / 14$ & $80 / 20$ & $73 / 17$ \\
\hline $\begin{array}{l}\text { Duration of opium } \\
\text { use (y) }\end{array}$ & $3 \pm 2$ & $3 \pm 2$ & 0 \\
\hline
\end{tabular}

In order to obtain the calibration curve and calculate the lead concentration in the sample, a standard solution of lead was injected into the voltammetry cell. This injection was performed twice with two different solutions and the mean value was taken for the calculation of different solutions $\triangleright$ Table 2 .

\section{Subjects}

Thirty hospitalized patients in the internal ward of the Sina hospital affiliated in the Tabriz University of Medical Sciences with acute lead poisoning (BLL higher than $80 \mu \mathrm{g} / \mathrm{dl}$ ) ranging from 16 to 73 years old participated in this study. Diagnosis of acute lead poisoning was confirmed by clinical and paramedical findings. The patients were assigned to the oral group ( $n=15$ subjects), which were receiving the opium by oral usage, and inhale group ( $n=15$ subjects), which were receiving the opium by inhalation usage. A healthy and normal control group ( $n=15$ subjects) with the following exclusion criteria was also used in this study. occupations susceptible to lead contamination such as painting, mining workers and gas station workers. The qualified subjects were first informed of the study purpose. Written, informed consent was then obtained from all the subjects, and the study was approved by the Tabriz University of Medical Sciences Ethics Committee. The subjects' characteristics such as sex, age, occupation, duration of opium use, history of any diseases, and place of living were recorded before the study.

A sufficient validation is an important point of chemical analysis in quantitation measurements. In order to validate the polarography method used in this study, the following parameters were obtained: 1) calibration curve (current-standard concentration of lead) by using the standard addition method, 2) linearity of the calibration curve, 3) limit of detection (LOD), 4) limit of quantification (LOQ), 5) accuracy, and 6) precision. LOD and LOQ are obtained from 3 folds and 10 folds of SD of the calibration curve over the slope of the calibration curve, respectively. To calculate the accuracy and precision, 3 known concentrations of lead solutions ( 50 , 100 , and 200 ppm), each 3 times, were manually spiked to the volammetric cell. The corresponding concentrations were calculated by the instrument automatically. If the calculated percent concentrations of lead is between 85 and $115 \%$, it is proved that the method is accurate. If the relative SD of currents is a lesser than $15 \%$, then the method is said to be precise [24]. Accuracy and precision measurements were repeated tree times and the mean of the measurements was used for statistical analysis.

To ensure the concurrent validity of BLL measurement in oral, inhale, and control groups, 10 other hospitalized people with lead poisoning participated in this study. Similar to the groups, a two $\mathrm{mL}$ of whole blood sample was used to measure BLL using the GFAAS (the standard method) and the other $2 \mathrm{~mL}$ with the current polarography method to compare the results of the BLL measurements.

\section{Statistical analysis}

The mean BLL was calculated for all subjects in the oral, inhale, and control groups. Statistical analysis was performed using Statistical Package for Social Sciences (SPSS, version 21.5). The outcome measures of each group were compared between the oral and control groups as well as between the inhale and control groups using independent samples t test and ANOVA. The comparison of the results between GFAAS and polarography methods was performed by using independent samples t test too. Significance was accepted for values of $\mathrm{p}<0.05$ in all analysis.

\section{Results}

Forty-five subjects with an average ( \pm SD) age of $42 \pm 18$ years, including $75.6 \%$ male and $24.4 \%$ female. The average duration of

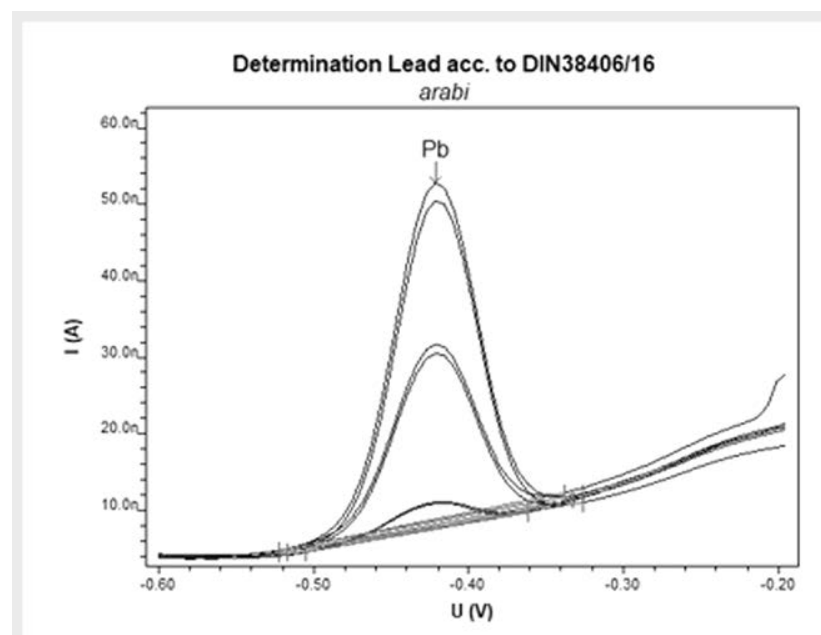

- Fig. 1 A representative voltagarm from BLL measurement. Red line, baseline; Blue cure, voltagarm obtained following blood sample injection with unknown concentration; black cure 1, internal standard injections with a single known concentration; black cure 2, internal standard injections with a double known concentration. 
opium use in oral and inhale groups was $4 \pm 2$ years. The measurements in oral and inhale groups were compared with the healthy and normal control group which were not receiving any opium.

The voltagram resulting from BLL measurement for all subjects participated in this study was obtained using DPASV. A representative voltagarm by a subject is presented in $>$ Fig. 1 . This voltagram shows that the peak current $(\mathrm{I}, \mathrm{n} \mathrm{A})$ which is obtained in $-0.420 \mathrm{~V}$ positively correlated with the BLL in blood sample injection (unknown concentration, blue curve), internal standard injection with a single (black curve 1) and double (black curve 2) known concentration.

In order to obtain the unknown concentration of BLL measurement in blood sample of the subjects, the calibration curve (peak current - lead concentration) was plotted using the peak current values calculated in single and double known concentrations ( $\triangleright$ Fig. 2). The BLL value in blood samples of the subjects (unknown concentration) is then obtained by plotting the regression line in this calibration curve (red downward arrow equivalent with $4.9364 \pm 0.089 \mu \mathrm{g} / \mathrm{dL}$ in Fig. 2).

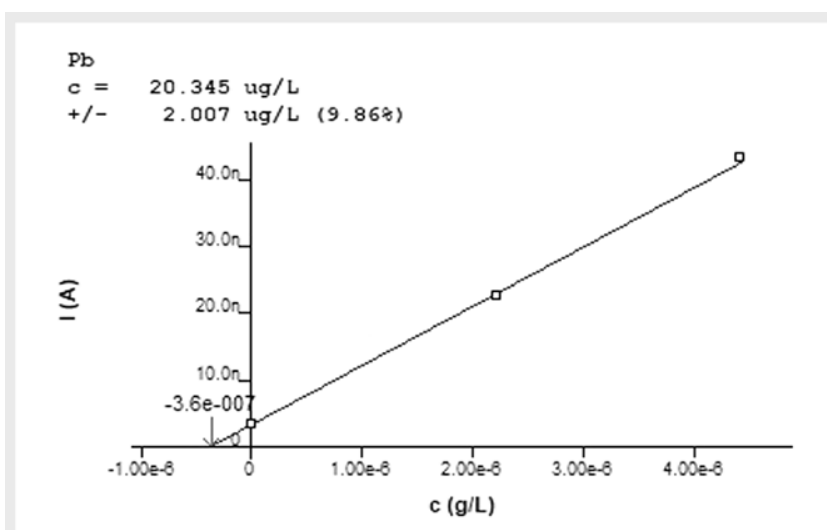

- Fig. 2 A representative calibration curve (peak current - lead concentration). Red downward arrow indicates the BLL value in blood sample.

- Table 3 BLL measurement (mean \pm SD) of the study subjects in GFAAS and polarography methods.

\begin{tabular}{|l|l|l|}
\hline BLL measurement & GFAAS $(\mathbf{n}=\mathbf{1 0})$ & Polarography $(\mathbf{n}=\mathbf{1 0})$ \\
\hline Mean $\pm S D(\mu \mathrm{g} / \mathrm{dl})$ & $45.31 \pm 17.23$ & $45.34 \pm 17.24$ \\
\hline P value & 0.997 & \\
\hline
\end{tabular}

- Table 4 Validation parameters of the polarography using the calibration curve obtained by the standard addition method.

\begin{tabular}{|l|l|}
\hline Parameters & Value \\
\hline Linearity equation & $\mathrm{Y}=7.823 \mathrm{X}+6.870083$ \\
\hline $\mathrm{R}^{2}$ & 0.9999 \\
\hline $\mathrm{LOD}(\mu \mathrm{g} / \mathrm{dl})$ & 0.0732 \\
\hline $\mathrm{LOQ}(\mu \mathrm{g} / \mathrm{dl})$ & 0.2440 \\
\hline Accuracy $(\%)$ & 95.76 \\
\hline Precision $(\mathrm{RSD}) \%)$ & 3.52 \\
\hline
\end{tabular}

The comparison of the BLL measurement between the GFAAS and the polarography methods showed that there were no statistically significant difference in mean BLL $(P>0.05)$ as shown in - Table 3.

The validation of the polarography method used in the current study approved by the calibration curve parameters which is shown in Table 4.

The mean of the BLL measurement in subjects participated in oral, inhale, and control groups are given in $>$ Table 5 . The results of the statistical analysis of the mean BLL measurements showed that the mean BLL measurement is significantly greater in oral group compared with the control group $(P<0.001)$. The similar result was also obtained when compared the mean BLL measurement between inhale and control group $(P<0.001)$.

There was a significant difference between the control group and the oral users group $(p<0.0003)$ and inhaled users group $(p<0.0001)$.

\section{Discussion}

The results of the current study were that the polarography is a rapid and valid method to determine BLL in people suffering from lead poisoning and that the amount of BLL is greater in people taking opioids orally compared with inhaled and healthy control groups. The whole procedure to measure BLL by using polarography method usually takes approximately 90 minutes, whereas the other methods such as FAAS, GFAAS, ICP-MS take very longer time to obtain the result. This is associated with the main advantage of the polarography method in which the time period of balancing to obtain a stable signal is significantly shorter than the above mentioned methods. Its worth mentioning that the digestion stage is almost similar in all methods. Another advantage of the polarography is related to its cost, which is very cheap compared to the AAS and ICP-MS.

Our study showed that polarography method is as valid as the GFAAS, which is a standard method in BLL measurement, as the comparison of the BLL measurements obtained from GFAAS and polarography revealed that there was no significant difference in BLL ( $\triangleright$ Table 3). Validity of BLL measurement by using polarography method in our study was also confirmed by the validation parameters ( $\triangleright$ Table 4). A very high regression coefficient $\left(r^{2}=0.9999\right)$ and the values of $\operatorname{LOD}(0.0732 \mu \mathrm{g} / \mathrm{dl})$ and $\operatorname{LOQ}(0.244 \mu \mathrm{g} / \mathrm{dl})$ imply that the lesser amount of BLL is detectable using polarography method. The minimum BLL measurement in our study was $2 \mu \mathrm{g} / \mathrm{dl}$, while LOQ of $0.244 \mu \mathrm{g} / \mathrm{dl}$ indicates that approximately eight times lesser than the minimum value could be determined in this study. The accuracy of $95 \%$ and precision (RSD\% $=3.52$ ) further confirmed the validity of BLL measurements. Fallowing the validation study, BLL measurements in people with lead poising showed that BLL was statistically greater in people who was taking opium orally com-

- Table 5 BLL measurement (mean \pm SD) of the study subjects in oral, inhale, and control groups.

\begin{tabular}{|l|l|l|l|}
\hline BLL measurement & Oral $(\mathbf{n = 1 5})$ & Inhale $(\mathbf{n}=\mathbf{1 5})$ & Control $(\mathbf{n}=\mathbf{1 5})$ \\
\hline Mean $\pm S D(\mu \mathrm{g} / \mathrm{dl})$ & $74.61 \pm 17.12$ & $19.33 \pm 2.257$ & $4.67 \pm 0.34$ \\
\hline P value & 0.0003 & 0.0001 & - \\
\hline
\end{tabular}


pared to the healthy control group. Similar result was also obtained in people who was taking opium by inhale ( $>$ Table 5 ). We also observed that, the BLL measurements was significantly greater in oral compared to the inhale usage of opium.

Unlike our results, in some studies difference in BLL measurements was not significant in people taking opium by different forms of opium consumption $[25,26]$. This maybe contributed to the evident mean BLL in oral and inhale groups in these studies (about $30 \mu \mathrm{g} / \mathrm{dl}$ compared to 19 and $74 \mu \mathrm{g} / \mathrm{dl}$ in our study) as well as the demographic characteristics of subjects, i. e., the participants in these studies were opium addict people whereas in our study they were hospitalized with acute lead poisoning diagnosis. Needless to say that the duration of opium use in participants could also be associated with the difference in BLL measurements. Our participants with different forms of opium consumption had no difference regarding demographic, clinical and biochemical characteristics except for job, platelet count and history of coma and weakness. Results of this study showed that both inhaled and oral forms of opium use can increase the blood levels of lead among users.

Recently, few studies reported lead poisoning following opium addiction among Iranian consumers [27-30]. Moreover, some evidence of the presence of lead within the opium have been reported in Southeast of Iran similar to our results, showed that the mean BLL in opium addicts was significantly higher than that among nonaddict subjects [30-32]. However, Beigmohammadi et al. did not find any difference between these two groups [26]. Aghaee-Afshar et al. reported considerable evidence of harmful amounts of lead within opium samples which had been provided illegally in some hidden laboratories [33]. Lead absorption via the respiratory system is the most common route of opium abuse among Iranian adults with a higher bioavailability, and approximately, $40 \%$ absorption. In addition, most of the manifestations of lead poisoning are similar to the symptoms of opium abuse such as nausea, vomiting, constipation, anorexia, and neuropsychological symptoms [25].

Our univariate and multivariate analyses showed no differences between crude and adjusted effects of opium use between both groups. This fact indicates that the adjusted factors such as gender and age did not have any confounding effect on the association between opium use and BLL. One of the limitations of this study is cross-sectional design of the study. It means that we cannot assess the temporal relationship between opium use and serum lead level. Moreover, it is difficult to make an association between lead poisoning and some clinical symptoms such as coma among study participants due to many unknown or unmeasured potential confounders. Unfortunately, we did not measure the amount of daily consumption due to non-reliable answers. Therefore, we did not investigate the association between symptoms and the amount of opium used. Mercury and most of its compound are highly toxic to human, ecosystems and wildlife. Mercury emissions from anthropogenetic source in EU-17 amounted to approximately 87 tonnes in 2008 while emissions to water were estimated to be around 10 tonnes in 2007. The health and environmental risk associated with mercury have led the European (EU) to developa comprehensive strategy addressing concerning mercury.

\section{Conclusions}

From the results of this study we concluded that BLL in people with lead poisoning due to opium addiction needs to be measured as soon as possible. In order to prevent any possible toxic effects of lead in various organs of the human body, the polarography method as a rapid, accurate, and inexpensive method recommended to measure BLL in people with opium addict.

\section{Acknowledgments}

The authors would like to thank the support of the Vice-chancellor of Research of Tabriz University of Medical Sciences (Code of ethics committee: 1369.12).

\section{Conflict of Interest}

The authors have no conflict of interest to declare.

\section{References}

[1] Brown LM, Kim D, Yomai A et al. Blood lead levels and risk factors for lead poisoning in children and caregivers in Chuuk State, Micronesia. International Journal of Hygiene and Environmental Health 2005; 208 : 231-236

[2] Leighton J, Klitzman S, Sedlar S et al. The effect of lead-based paint hazard remediation on blood lead levels of lead poisoned children in New York City. Environmental Research 2003; 92: 182-190

[3] Okhovat AA, Ansari B, Basiri K et al. Neuromuscular manifestations of lead poisoning in opium and herbal users in Iran. Revue Neurologique. 2020-03-03, DOI: 10.1016/j.neurol.2019.12.004

[4] Stierman B, Hauptman M, Woolf AD. Severe lead poisoning requiring hospitalization: A case report. Current Problems in Pediatric and Adolescent Health Care 2020; 100757

[5] Zamani N, Hassanian-Moghaddam H, Bahrami-Motlagh $\mathrm{H}$ et al. Lead poisoning due to ingestion of lead-contaminated opium: A diagnostic study on patients' imaging findings. Journal of Trace Elements in Medicine and Biology 2019; 55: 26-32

[6] Zhang Y, O'Connor D, Xu W et al. Blood lead levels among Chinese children: The shifting influence of industry, traffic, and e-waste over three decades. Environment International 2020; 135: 105379

[7] van den Heever L, Smit-Robinson H, Naidoo $V$ et al. Blood and bone lead levels in South Africa's Gyps vultures: Risk to nest-bound chicks and comparison with other avian taxa. Science of The Total Environment 2019; 669: 471-480

[8] Wani AL, Ara A, Usmani JA. Lead toxicity: A review. Interdisciplinary Toxicology 2015; 8: 55-64

[9] Tchounwou PB, Yedjou CG, Patlolla AK et al. Heavy Metal Toxicity and The Environment Springer. 2012; 24 April 2012. doi.org/10.1007/9783-7643-8340-4_6

[10] Dinis MDL, Fiuza A. Exposure assessment to heavy metals in the environment: measures to eliminate or reduce the exposure to critical receptors Springer. 2011; 1

[11] Ghaemi K, Ghoreishi A, Rabiee N et al. Blood Lead Levels in Asymptomatic Opium Addict Patients; a Case Control Study. Emergency.. 2017; 5 (1): e69

[12] Lin G-z Wu F, Yan C-h et al. Childhood lead poisoning associated with traditional Chinese medicine: A case report and the subsequent lead source inquiry. Clinica Chimica Acta 2012; 413: 1156-1159 
[13] Shannon M. Severe Lead Poisoning in Pregnancy. Ambulatory Pediatrics 2003; 3: 37-39

[14] Shukla V, Shukla P, Tiwari A. Lead poisoning. Indian Journal of Medical Specialities 2018; 9: 146-149

[15] Yabe J, Nakayama SMM, Ikenaka Y et al. Lead poisoning in children from townships in the vicinity of a lead-zinc mine in Kabwe, Zambia. Chemosphere 2015; 119: 941-947

[16] Alinejad S, Aaseth J, Abdollahi M et al. Clinical aspects of opium adulterated with lead in Iran: a review. Basic \& Clinical Pharmacology \&. Toxicology 2018; 122: 56-64

[17] Organization WH. Brief guide to analytical methods for measuring lead in blood. 2011; https://apps.who.int/iris/handle/10665/77912

[18] Andrada, D., Pinto, F.G., Magalhães, C.G et al, Direct determination of lead in human urine and serum samples by electrothermal atomic absorption spectrometry and permanent modifiers. Journal of the Brazilian Chemical Society,2006; 17(2): 328-332.

[19] Wang J. Stripping analysis. Encyclopedia of Electrochemistry: Online. 2007

[20] Afshari R, Emadzadeh A. Case report on adulterated opium-induced severe lead toxicity. Drug and Chemical Toxicology 2010; 33: 48-49

[21] Abolhasani F, Amani MA, Aghamollaei H et al. Simultaneous determination of Zinc and Lead in blood samples by Differential Pulse Polarography. Journal of Applied Biotechnology Reports 2015; 1 : 171-174

[22] Zapata-Flores E, Gazcón-Orta N, Flores-Vélez L. A direct method for the determination of lead in beers by differential pulse polarographyanodic stripping voltammetry. 2016, 7 (12): 4467-4470

[23] Mortazavi S, Farmany A. Analysis of Lead in Blood Serum Samples by Voltammetry Method. World Applied Sciences Journal 2011; 15: 606-610
[24] Bass DA, Hickok D, Quig D et al. Trace element analysis in hair: Factors determining accuracy, precision, and reliability. Alternative Medicine Review 2001; 6: 472-481

[25] Nemati A, Jafari S, Afshari M et al. Comparing Blood Lead Level among Oral/inhaled Opium Addicts with a Non-addict Control Group in the Southeast of Iran. Addiction \& health 2016; 8: 235

[26] Beigmohammadi MT, Aghdashi M, Najafi A et al. Quadriplegia due to lead-contaminated opium. MEJ ANESTH 2008; 19: 1411-1416

[27] Khatibi-Moghadam H, Khadem-Rezaiyan M, Afshari R. Comparison of serum and urine lead levels in opium addicts with healthy control group Human \& Experimental Toxicology 2016; 35: 861-865

[28] Alinejad S, Zamani N, Abdollahi M et al. A narrative review of acute adult poisoning in Iran. Iranian Journal of Medical Sciences 2017; 42: 327

[29] Karrari P, Mehrpour O, Abdollahi M. A systematic review on status of lead pollution and toxicity in Iran; Guidance for preventive measures. DARU. Journal of Pharmaceutical Sciences 2012; 20: 2

[30] Afzali S, Torabian S, Taheri SK. Do Opium Abusers Develop Lead Toxicity? A Study on Opium Abusers in Hamadan, Iran. Asia Pacific. Journal of Medical Toxicology 2017; 6: 55-58

[31] Salehi H, Sayadi AAR, Tashakori M et al. Comparison of serum lead level in oral opium addicts with healthy control group 2009;12 (6): 555-558

[32] Amiri M, Amini R. A comparison of blood-lead level (BLL) in opiumdependant addicts with healthy control group using the graphite furnace/ atomic absorption spectroscopy (GF-AAS) followed by chemometric analysis. Iranian Red Crescent Medical Journal 2012; 14: 488

[33] Aghaee-Afshar M, Khazaeli P, Behnam B et al. Presence of lead in opium. Arch Iran Med 2008; 11: 553-554 